\title{
OS MESOPOTÂMICOS TINHAM FOME DE QUÊ? LITERATURA, CULTURA MATERIAL E OUTRAS HISTÓRIAS
}

Katia Maria Paim Pozzer ${ }^{1}$

\section{Resumo}

As análises sobre a significação simbólica dos alimentos, os hábitos culinários e o comportamento à mesa foram impulsionadas pela Nova História Cultural e favoreceram os estudos sobre as relações entre alimentação, cultura e estrutura social. Assim, neste artigo pretendemos discutir o banquete mesopotâmico, suas raízes sagradas, os mitos de criação dos alimentos, a cultura material e a rica iconografia existente sobre o tema.

\section{Palavras-chave}

Mesopotâmia; alimentação; cultura material; literatura.

\begin{abstract}
The analyzes of the symbolic meaning of food, the culinary habits and the behavior at the table were stimulated by the New Cultural History and favored the studies on the relations between food, culture and social structure. Thus, in this article we intend to discuss the Mesopotamian banquet, its sacred roots, the myths of food creation, the material culture and the rich iconography on the subject.
\end{abstract}

Keywords

Mesopotamia; food; material culture; literature.

\footnotetext{
1 Professora Doutora, Universidade Federal do Rio Grande do Sul, Porto Alegre, Brasil. E-mail: katia.pozzer@ufrgs.b
} 
Participar de uma homenagem acadêmica ao Prof. Pedro Paulo de Abreu Funari é um privilégio, pois significa que, em algum momento de minha vida profissional, encontrei-me com o Pedro Paulo (como ele é afetuosamente chamado) e pude compartilhar de sua sabedoria e generosidade. Sem dúvida, o Prof. Funari é um dos expoentes brasileiros, da História e da Arqueologia, com maior inserção e reconhecimento internacional. Ele se fez exemplo de percurso acadêmico sério e prolífico como poucos no país. Assim, minhas pesquisas sobre a história da alimentação, tendo por base a interlocução entre a cultura material, especialmente sua visualidade, e os textos literários são inspiradas nos trabalhos de nosso homenageado.

As análises sobre a significação simbólica dos alimentos, os hábitos culinários e o comportamento à mesa foram impulsionadas pela Nova História Cultural e favoreceram os estudos sobre as relações entre alimentação, cultura e estrutura social (Flandrin; Montanari, 1998). Assim, neste artigo pretendemos discutir o banquete mesopotâmico, suas raízes sagradas, os mitos de criação dos alimentos, a cultura material e a rica iconografia existente sobre o tema.

A origem da agricultura e da pecuária na Mesopotâmia é tema da literatura de cunho mitológico. O texto a seguir, transcrito parcialmente, intitulado Ašnan contra Lahar, relata o surgimento dos cereais e dos animais de pequeno porte sobre a terra (Bottéro, 1993: 511-513)2:

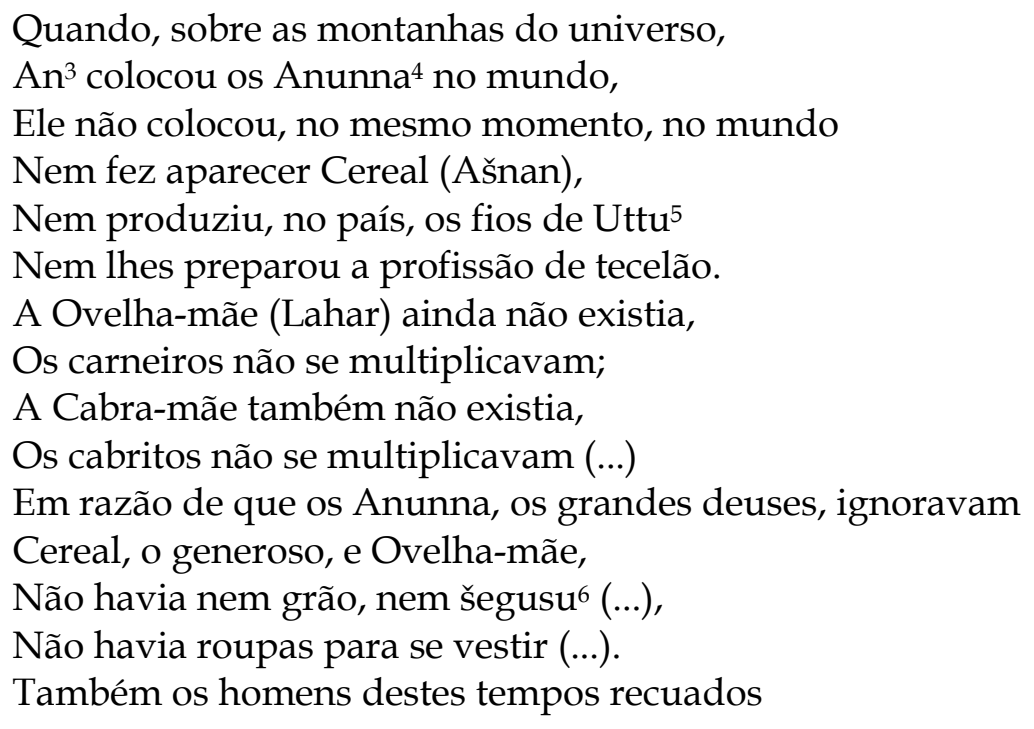

2 Todas as traduções dos textos em línguas modernas são da autora.

${ }^{3}$ An: divindade mesopotâmica líder dos deuses é, também, o nome sumério para céu.

${ }^{4}$ Divindades primitivas, os que foram criados primeiro e não são diferenciados entre si.

${ }^{5}$ Deusa suméria associada a tecelagem.

${ }^{6}$ Espécie de cevada amarga. 
Não sabiam nem comer o pão,

Nem se cobrir com as vestimentas:

Eles iam e vinham nus,

Se alimentando de relva, como fazem as ovelhas,

E bebendo somente água das nascentes nas montanhas.

É então, que em seu lugar de nascimento, nas montanhas sagradas,

Os deuses criaram Ovelha-mãe e Cereal, o generoso,

Que eles os introduziram juntos em suas refeições! (...)

Os Anunna das montanhas sagradas

Consumiram fartamente estes produtos

Da Ovelha-mãe e Cereal,

Sem, contudo, se saciarem.

Os Anunna das montanhas sagradas

Beberam o delicioso leite de seu estábulo,

Sem, contudo, se saciarem:

É por isso que eles concederam aos homens o sopro da vida.

Enki diz então à Enlilis:

Oh venerável Enlil, faça descer sobre a terra Ovelha-mãe e Cereal!

Foi assim que, sob ordem de Enki e Enlil,

Ovelha-mãe e Cereal desceram aqui em baixo desde as montanhas sagradas.

Neste texto, as duas divindades-protetoras dos alimentos, de origem vegetal e animal domesticados pelo homem desde o período Neolítico, discutem enquanto arquétipos de duas realidades diferentes e se comparam. Encontramos neste documento a explicação mitológica para a origem dos cereais usados na alimentação e no vestuário (linho) e dos animais de pequeno porte, cuja domesticação data do VII milênio aEC, e que faziam parte da dieta alimentar da maioria da população da época. Mas, também, está implícito, nas últimas seis linhas do documento, a causa do surgimento do homem sobre a terra, que é a de servir aos deuses.

Segundo a mitologia mesopotâmica, a criação do homem pelos deuses reponde à um motivo preciso: os humanos devem trabalhar para o sustento dos deuses e liberá-los de qualquer necessidade material. Dentro do imaginário mesopotâmico, os deuses apreciavam os mesmos alimentos que os homens: produtos da agricultura e pecuária. Estas provisões eram oferecidas cotidianamente nos templos, na forma de sacrifícios de sangue ou de oblações de produtos vegetais e bebidas. Por isso, o culto religioso é composto de abundantes oferendas alimentares às divindades, que gozavam de uma vida ociosa e agradável, onde o banquete tinha um lugar importante (Sigrist, 1984).

\footnotetext{
7 Enki, nome sumério do seu equivalente em acádico, Ea, o deus responsável pela criação do Homem, segundo a mitologia mesopotâmica.

8 O deus mais importante do panteão mesopotâmico, Enlil é o rei dos deuses.
} 
A epopéia mesopotâmica da criação, conhecida como Enuma Eliš, trata de questões ontológicas fundamentais, como o surgimento do universo, dos deuses e do homem. Nesse texto, também encontramos referências ao banquete. O poema, com sete cantos e um total de 1.100 versos, teria sido escrito durante o reinado de Nabucodonosor I (1124-1103 aEC). Acreditase que era um texto de estudo obrigatório nas escolas preparatórias de escribas e sacerdotes, sendo recitado durante as festas de Ano Novo.

No primeiro tablete é narrada a origem do universo, quando o céu e a terra ainda não tinham sido nomeados, portanto ainda não existiam. Havia somente um caos aquático primordial, contendo um elemento masculino, Apsu, a água doce, e um elemento feminino, Tiamat, a água salgada.

O segundo canto relata uma disputa entre Tiamat e as outras divindades e a convocação de uma reunião dos deuses para solucionar o conflito.

É no terceiro tablete que esta reunião é narrada de forma bastante suscinta (Peinado, 1994: 59-63):

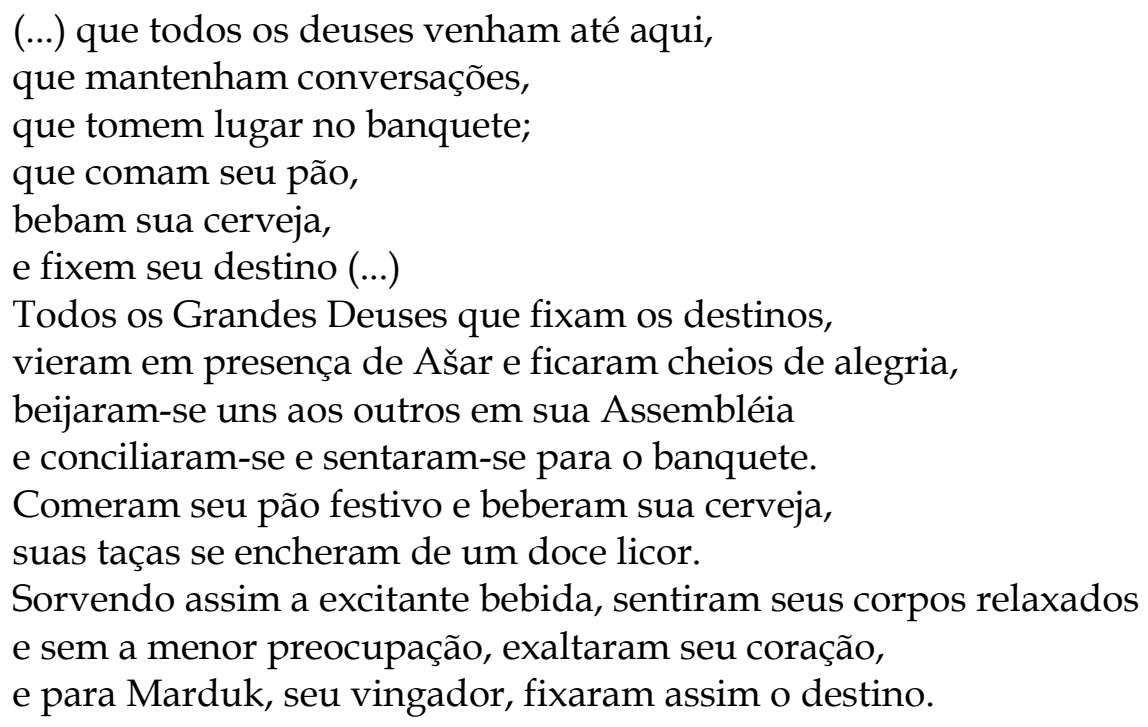

No decorrer deste banquete os deuses decidem escolher um dentre eles para lutar contra a deusa Tiamat e conferem ao deus Marduk ${ }^{9}$, então escolhido, plenos poderes.

Vemos, através da mitologia, o papel do banquete solene e coletivo, ele não é simplesmente o palco de uma refeição, do prazer da gastronomia, mas é a ocasião para os comensais tomarem decisões importantes visando seus próprios interesses. Isto é, o banquete adquire, além da reunião social, a função de caráter político. (Glassner, 2003: 45).

${ }^{9}$ Marduk era o deus-protetor da cidade de Babilônia. 


\section{Alimentação e Cultura Material}

As escavações arqueológicas do antigo Oriente Próximo possibilitaram a identificação de uma rica diversidade de produtos que constituíram a cozinha dos mesopotâmicos: cereais, legumes diversos, frutas - como a tâmara, maçã, pêra, figo, romã, uva - bulbos e raízes, trufas e cogumelos, ervas condimentares. Eles consumiam carnes de animais de pequeno e médio porte, suínos, aves (exceto os galináceos, vindos tardiamente), das quais ingeriam os ovos; e os animais de caça, peixes de água doce e salgada, crustáceos, mariscos e insetos, como o gafanhoto (Figs. 1 e 2), leite, manteiga e outras gorduras vegetais, especialmente o sésamo e a oliva, mel e produtos minerais, como o sal e as cinzas. (Stol, 2000: 496497).

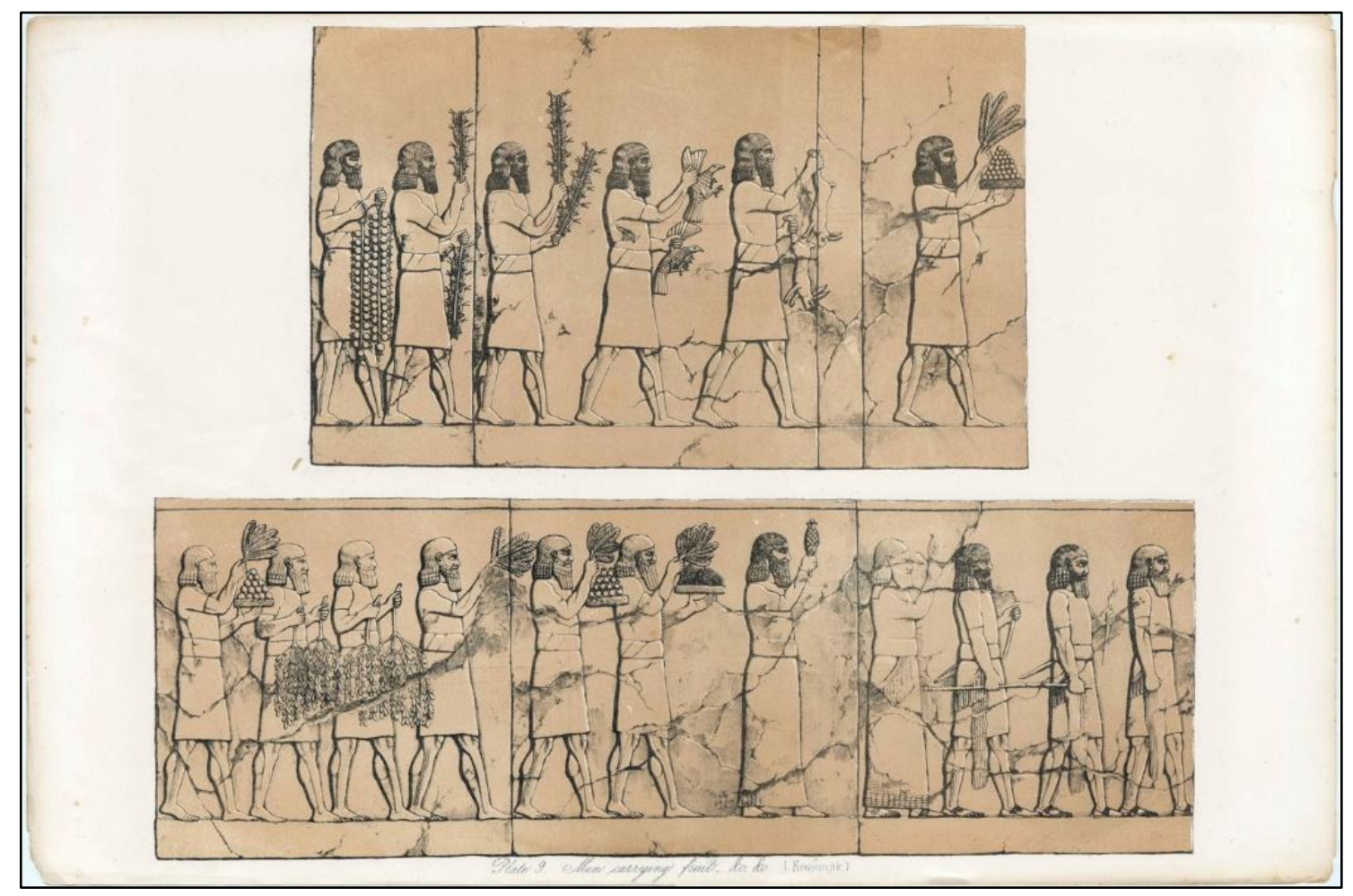

Fig. 1. Cena de preparação do banquete. Fonte: Layard, 1853, vol 1: 24. 


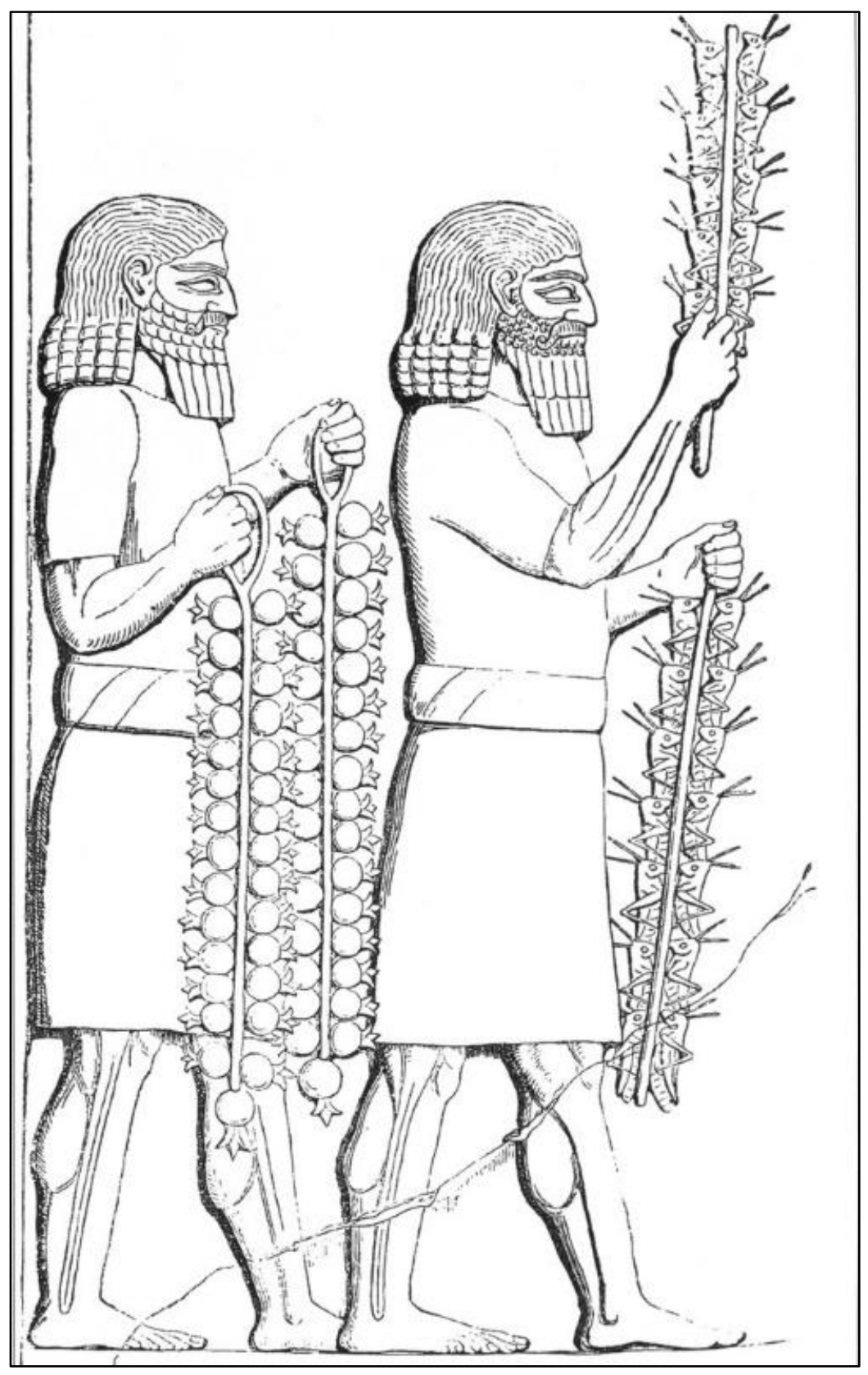

Fig. 2. Cena de preparação do banquete (detalhe). Fonte: Layard, 1853, vol 1: 24.

O consumo de carne bovina era realizado, preferencialmente, durante atividades festivas, tanto nos templos como nos palácios. A carne de animais de caça, como javali, gazelas e pássaros selvagens também era consumida, como podemos observar neste detalhe de baixo-relevo assírio (Fig. 3). Escavações arqueológicas realizadas em zonas habitacionais, no interior das cidades, encontraram uma diversidade de ossos de aves, testemunhando seu consumo generalizado entre os mesopotâmicos (Joannès, 2001: 911). 


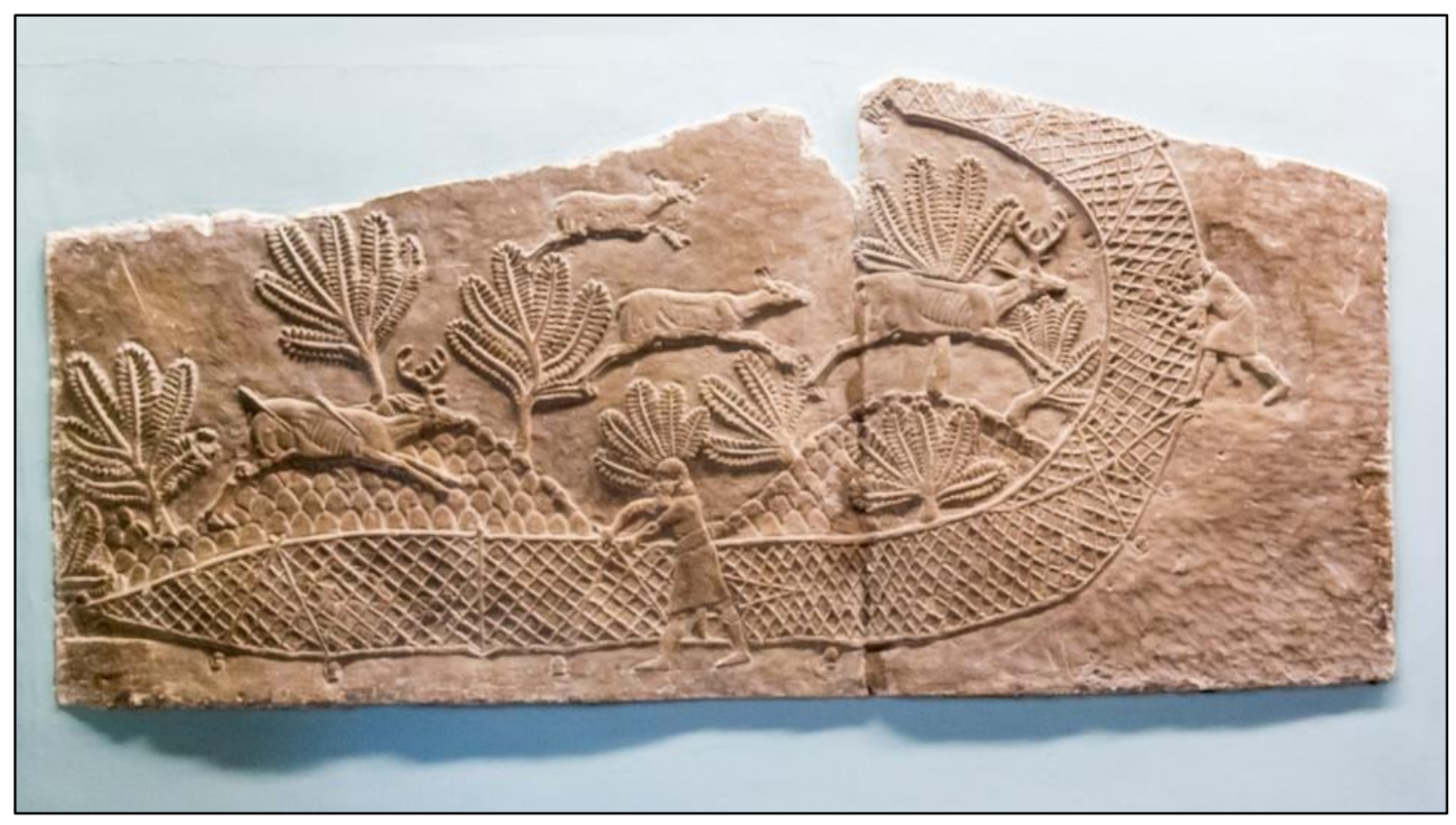

Fig. 3. Cena de caça ao cervo com rede, baixo-relevo em alabastro. Fonte: Assíria, 645635 AEC. Nínive, Palácio Norte, sala S. Museu Britânico. Foto da autora.

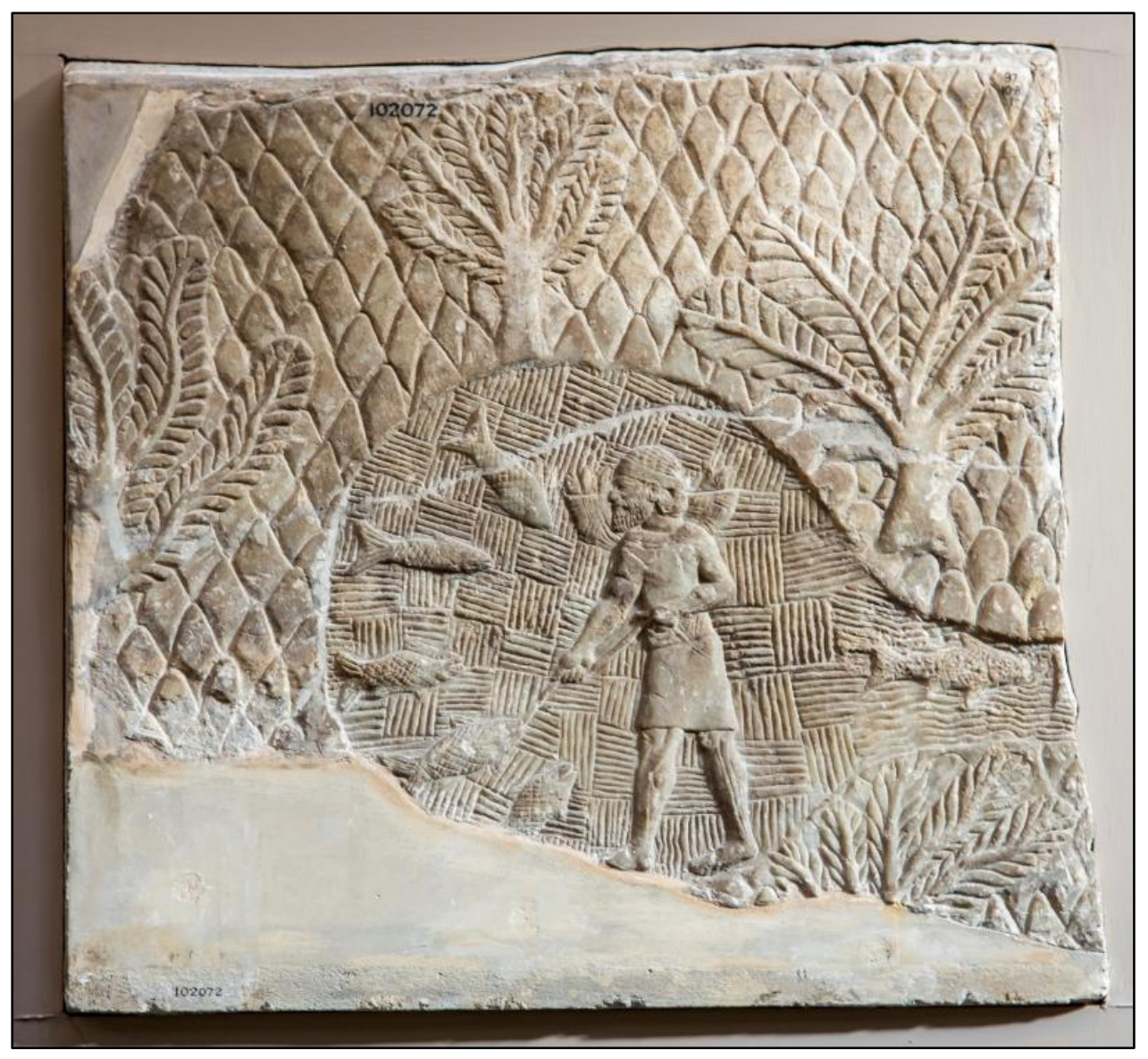

Fig. 4. Cena de pesca em um lago, com anzol, baixo-relevo em alabastro. Fonte: Assíria, 700-692 AEC. Nínive, Palácio Sudoeste, sala XLV. Museu Britânico. Foto da autora. 
Temos evidências que os mesopotâmicos criaram múltiplas maneiras de transformar os alimentos, desenvolvendo várias técnicas de conservação, sobretudo os alimentos secos ao sol: cereais, legumes e frutas (tâmara, uva e figo), carne e peixe, que, provavelmente, aprenderam a defumar; as conservas no sal ou no azeite: peixes e carnes diversas (Fig. 4); e as conservas no mel: frutas.

Produziram, também, uma salmoura usada como condimento e conserva, à base de peixes, crustáceos ou gafanhotos, chamada šiqqu, comparável ao garum romano e ao molho de ostras japonês dos dias de hoje. Sabe-se que utilizavam a fermentação láctea para produzir queijos frescos e uma espécie de iogurte. Podemos identificar a preparação da manteiga neste relevo de Tell el-Ubaid (Fig. 5).

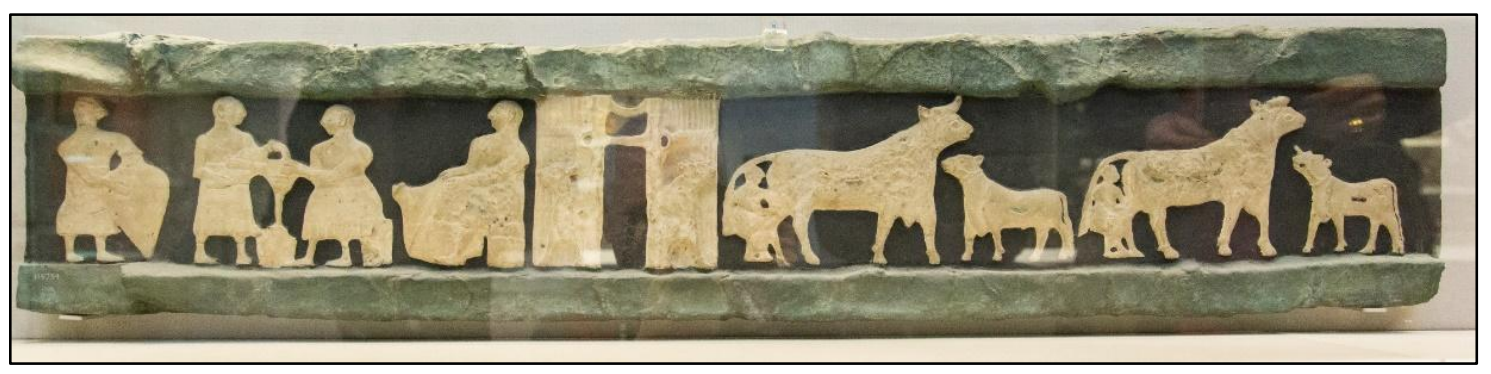

Fig. 5. Cena de preparação de manteiga, mosaico em marfim. Fonte: Templo de Ninhursag, Tell el-Ubaid, 2500 AEC. Museu Britânico. Foto da autora.

Os cereais eram moídos e peneirados para fazer sêmolas e farinhas de diferentes tamanhos de grãos. A partir destas farinhas eram produzidos fervidos e massas, que poderiam ser fermentadas ou não.

Os alimentos poderiam ser grelhados ou assados diretamente nas chamas ou cozidos mais lentamente sob brasas e cinzas. Os fornos também foram usados e o cozimento era em meio líquido - graxas animais e sobretudo água -, onde eram utilizados dois tipos principais de vasos: a panela em cerâmica (diqâru) e o caldeirão em bronze (ruqqu).

Dentre a rica documentação sobre o mundo tangível produzida pelos escribas mesopotâmicos está o Material Sumerian Lexicon (MSL), um catálogo bilíngüe, em duas colunas, em sumério e em acádico, de todos os componentes materiais do mundo mesopotâmico, classificados em diversas categorias. Os textos estão organizados em 24 tabletes, com 400 rubricas temáticas cada um, sendo que as duas últimas foram reservadas ao setor "Alimentação". Desta lista podemos extrair 18 ou 20 qualidades de queijos, uma centena de tipos de sopas (sumério TU, acádico ummaru), cerca de 300 qualidades de pães (variando a farinha, fermento, azeite, leite ou cerveja, doce ou temperado, com frutas, etc.), onde a forma 
também variava (pequenos ou grandes, espessos ou finos, em forma de coração, cabeça, mão, orelha, animais ou divindades) (Figs. 6, 7 e 8). A questão estética do alimento era tamanha que o título acádico para o responsável da cozinha, o equivalente ao atual chef de cuisine, era mubannû, cuja tradução literal é "o embelezador".

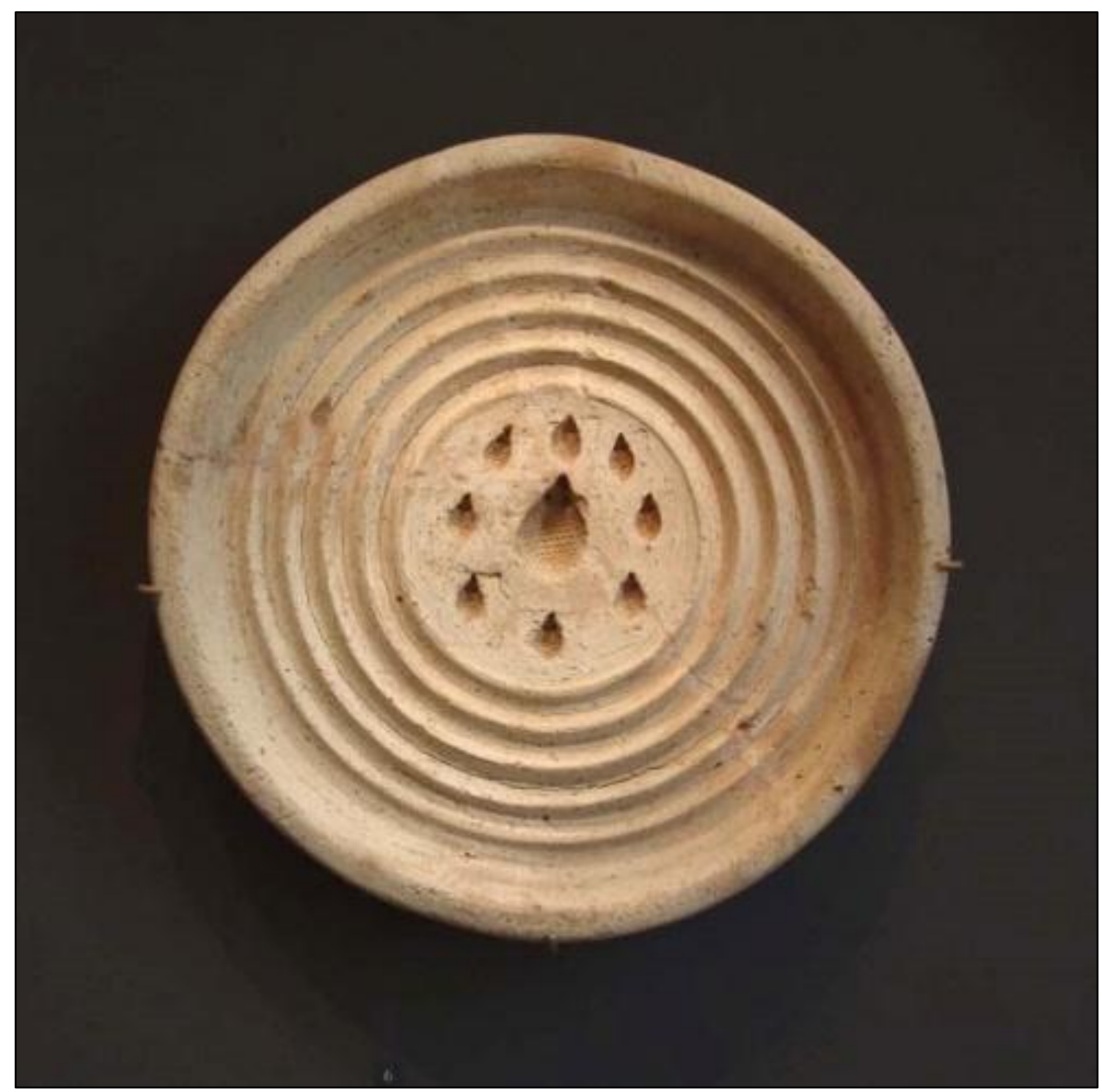

Fig. 6. Fôrma de pão em argila. Palácio de Mari, sala 77. Início do II milênio aEC. Fonte: Museu do Louvre. Foto da autora.

A mais antiga receita culinária conhecida, datada do começo do II milênio aEC, poderia ser chamada de Pão de Mel e Especiarias, mersu, em acádico e ninda.dé.a em sumério, e tinha como ingredientes: farinha, água, leite ou cerveja, azeite ou manteiga para umidificar, além de tâmaras e frutas secas, como uvas, figos ou maçãs e uma espécie de pinhão. Era temperada com quatro condimentos aromáticos: nigela, 
cominho, coriandro e de alho, e adoçada com mel. A aparência final do prato era de um pão cozido no forno. (Bottéro, 1995).

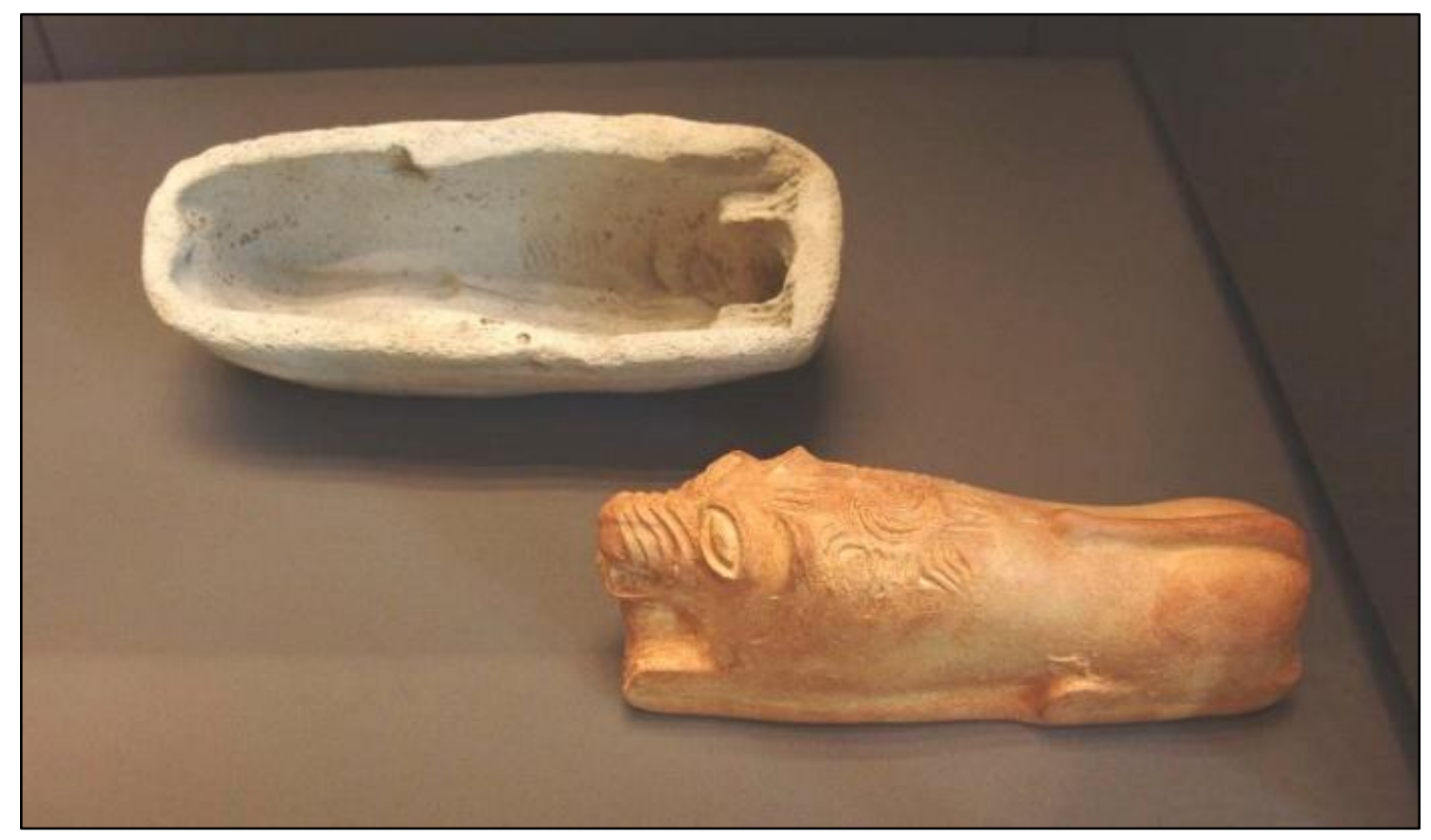

Fig. 7. Fôrma de pão em argila e réplica moderna. Palácio de Mari, sala 77. Início do II milênio aEC. Fonte: Museu do Louvre. Foto da autora.

Mas além de comer, os mesopotâmicos também bebiam. A cerveja, considerada a bebida mais popular e mais antiga na região, pois é anterior ao III milênio aEC, era um ingrediente fundamental em qualquer banquete na Mesopotâmia. Esta bebida fermentada, à base de cereais, era preparada, segundo técnicas aprimoradas, de mais de 30 maneiras diferentes: branca, vermelha, clara, escura, adoçada ao mel e perfumada com múltiplos aromas. Em geral, bebia-se coletivamente, aspirando, em uma mesma jarra, com canudos com uma espécie de filtro na extremidade, afim de eliminar as impurezas da mesma.

$\mathrm{Na}$ antiga Mesopotâmia, a cerveja era considerada um presente dos deuses, um demarcador da civilização, um alimento básico e uma necessidade ritual. Foi produzida em grande escala e consumida diariamente por pessoas das mais diversas camadas socioeconômicas. $\mathrm{Na}$ verdade, a cerveja era "pão líquido", uma fonte fundamental de sustento. Mas o que deu à cerveja o seu poder e apelo distintivo foram seus efeitos inebriantes. 


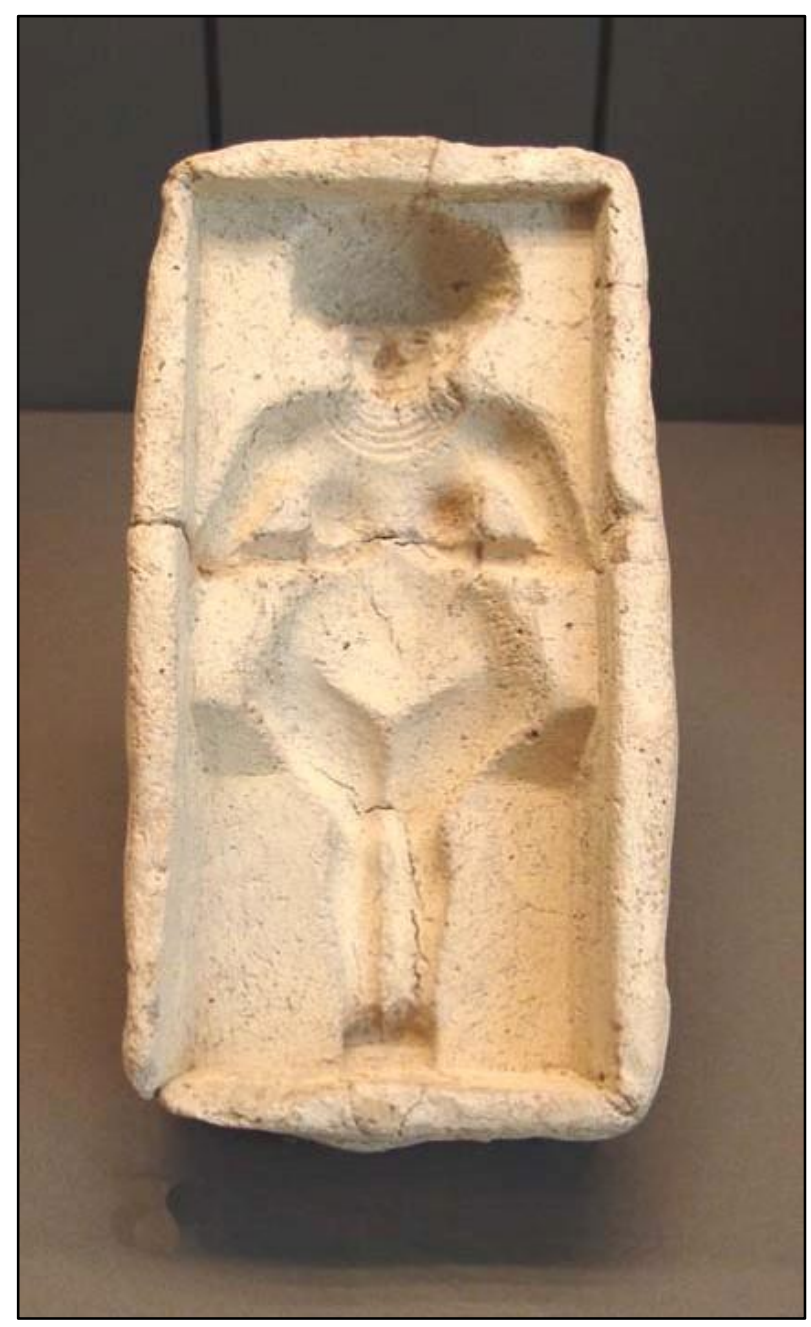

Fig. 8. Fôrma de pão em argila. Palácio de Mari, sala 77. Início do II milênio aEC. Fonte: Museu do Louvre. Foto da autora.

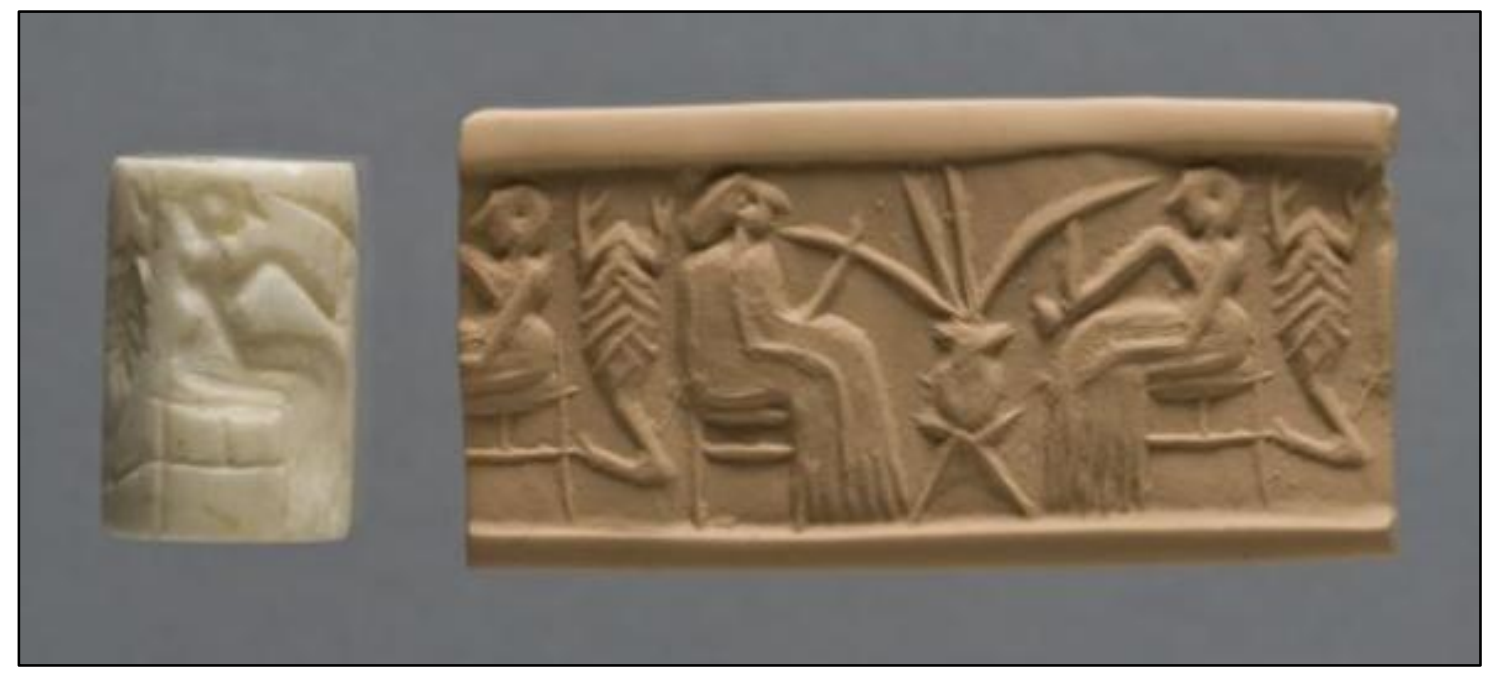

Fig. 9. Sêlo-cilindro em alabastro e impressão moderna. Período Dinástico Antigo (2600-2350 AEC). 21 X 14 mm. Khafajeh, Iraque. Fonte: Instituto Oriental de Chicago. 
Conhecida como kaš em sumério ou šikaru em acádico, era uma bebida fermentada à base de cevada, tipicamente fabricada com dois ingredientes-chave: cevada maltada e um tipo especial de pão de cevada chamado bappir. A melhor descrição do próprio processo de fabricação pode ser encontrada em um documento literário, o famoso Hino a Ninkasi, deusa da cerveja:

Dado o nascimento pela água corrente [...], ternamente cuidada por Ninhursaja! Ninkasi, dado à luz pela água que flui [...], ternamente cuidada por Ninhursaja!

É você que manipula [...] e amassa com uma grande pá, misturando, em um poço, o pão de cerveja com aromas doces. Ninkasi, você é quem manipula o [...] e amassa com uma grande pá, misturando, em um poço, o pão de cerveja com aromas doces.

Você coloca o vaso de fermentação, o que faz um som agradável, apropriadamente em cima de um grande coletor. Ninkasi, você coloca o vaso de fermentação, o que faz um som agradável, apropriadamente em cima de um grande coletor.

É você que derrama a cerveja filtrada do coletor; é como a invasão do Tigre e do Eufrates. Ninkasi, é você quem derrama a cerveja filtrada do coletor; é como a invasão do Tigre e do Eufrates. ${ }^{10}$

Segundo um dos textos literários mais importantes da civilização mesopotâmica, datado do I milênio aEC, e conhecido como a Epopéia de Gilgameš, beber cerveja fazia parte do processo civilizatório de Enkidu, o amigo de Gilgameš, que, inicialmente, era uma criatura selvagem, que vivia em meio aos animais: primeiro ele teve relações sexuais com uma mulher, uma cortesã, durante seis dias e sete noites; depois ele comeu pão e bebeu cerveja, depois se lavou e se perfumou e vestiu roupas limpas. Foi assim que ele tornou-se um homem civilizado! (Pozzer, 2014). Reproduzimos algumas linhas do texto, do $2^{\circ}$ tablete, $1^{a}$ coluna (Bottéro, 1992c: 224):

Enkidu não conhecia o pão como alimento; ele ignorava a cerveja como bebida. A cortesã, abrindo a boca, diz à Enkidu: "coma o pão, Enkidu, é o sinal da vida civilizada; beba a cerveja, é o costume no país civilizado". Enkidu comeu o pão até saciar-se, bebeu a cerveja sete vezes, seu coração relaxou e ele se pôs a cantar alegremente...

Os mesopotâmicos também conheciam o vinho, proveniente da região norte e nordeste. $\mathrm{O}$ vinho era uma bebida rara, considerada de luxo, onde somente os deuses e os reis teriam o privilégio de consumi-la. A palavra GEŠTIN, em sumério, designava, ao mesmo tempo, a videira e o vinho. A vinha teria sido plantada na Suméria para consumo da uva. $\mathrm{O}$ vinho era

10 http://etcsl.orinst.ox.ac.uk/section4/c4231.htm 
importado das regiões montanhosas da Síria e Armênia (Lion; Michel, 2001:139).

\section{A Estela de Kalhu - um documento excepcional}

A inauguração de palácios reais foi uma ocasião privilegiada para a realização de grandes banquetes. E dentre os mais documentados encontra-se o suntuoso banquete oferecido por Assurnazirpal II (883-859 a.C.), rei assírio, quando inaugurou a nova capital de seu reino, a cidade de Kalhu. A cidade, conhecida pelo nome bíblico de Kalah, encontra-se, atualmente, no Iraque, no sítio arqueológico de Nimrud, a cerca de $25 \mathrm{~km}$ ao sul de Mossul. Este relato está registrado em uma estela de pedra, encontrada no local em 1951 (Joannès, 1998: 62). Trata-se de um texto único, onde estão enumeradas as campanhas militares, as importações de árvores para ornar os jardins reais e a evocação do banquete (Pritchard, 1975: 99):

Quando Assurnazirpal, rei da Assíria, inaugurou o palácio da alegria, o palácio repleto de sabedoria, da cidade de Kalhu, ele convidou o deus Aššur, o grande Senhor e os deuses de todo o país.

100 bois gordos, 1.000 terneiros e ovelhas da criação real, 14.000 ovelhas compradas, pertencentes à deusa Ištar, minha Dama, (...), 1.000 patos grandes, 500 gansos, 10.000 pombas, 10.000 peixes, (...), 10.000 ovos. 10.000 pães, 10.000 jarros de cerveja, 10.000 outros de vinho, 10.000 recipientes de grão-debico e de sésamo, (...), 1.000 caixas de legumes, 300 recipientes de óleo, 300 recipientes de finas ervas. 100 recipientes de romãs, 100 recipientes de uva, 100 recipientes de frutas sortidas, 100 recipientes de alho, 100 recipientes de cebola, (...),100 recipientes de mel, 100 recipientes de lentilhas, 100 recipientes de mostarda, 100 recipientes de leite, 100 recipientes de queijo, (...).

Quando eu inaugurei o palácio da cidade de Kalhu, 47.074 homens e mulheres que foram convidados de todos os distritos de meu país, 5.000 dignitários e enviados de povos de países de Suhu, Tiro, Sidon, (...), um total de 69.574 pessoas, durante 10 dias eu os alimentei, eu dei-lhes de beber, eu ofereci-lhes banho e óleos (perfumados). Assim eu os honrei e os reenviei de volta ao seu país em paz e felizes.

Os números apresentados neste relato podem ser fictícios, mas, de qualquer forma, atestam a grandiosidade desta inauguração e a astúcia do rei assírio em demonstrar seu poder e garantir a preservação da memória deste importante evento histórico, além de revelar um aspecto das práticas de sociabilidade da época. 


\section{Conclusão}

A iconografia dos mosaicos, os objetos arqueológicos e a documentação epigráfica revelam a importância social do prazer à mesa no mundo mesopotâmico. No imaginário babilônico, comer e beber juntos servia para fortalecer a amizade entre os iguais e para reforçar as relações entre o rei e seus súditos. A partilha do alimento, mais do que a própria composição da refeição, era o mais importante. $O$ que fundava o banquete era esta comensalidade entre os participantes e remetia a uma das expressões da solidariedade básica da comunidade.

É importante notar que os textos literários também forneceram informações sobre as técnicas de preparo dos alimentos e as preferências alimentares da corte.

O banquete também era um ato político, ritualizado e sagrado. Com ele selavam-se acordos de paz entre os homens e garantia-se a proteção divina para que a vida na terra fosse mais próspera e mais feliz.

Na Mesopotâmia, as grandes decisões sobre questões do universo, da natureza e da cultura, foram tomadas pelos deuses à mesa, em meio a um grande banquete.

\section{Referências Bibliográficas}

BLACK, J., GEORGE, A.; POSTGATE, N. A Concise Dictionary of Akkadian. Wiesbaden: Harrassowitz Verlag, 2000.

BLACK, J.; GREEN, A. Gods, demons and symbols of Ancient Mesopotamia. London: British Museum Press, 1998.

BORGER, R. Assyrisch-babylonische Zeichenliste. Neukirchen-Vluyn: Verlag Butzon \& Bercker Kevelaer, 1978.

BOTTÉRO, J. La plus vieille cuisine du monde. In: BOTTÉRO, J. Iniciation à l'Orient ancien. Paris: Éditions du Seuil, 1992a. p.81-101.

Le plus vieux festin du monde. In: BOTTÉRO, J. Iniciation à l'Orient ancien. Paris: Éditions du Seuil, 1992b. p.104-121.

- Textes Culinaires Mésopotamiens - Mesopotamian Culinary Texts. Winona Lake: Eisenbrauns, 1995. 
L'Épopée de Gilgameš - Le grand homme qui ne voulait pas mourir. Paris: Gallimard, 1992c.

BOTTÉRO, J.; KRAMER, S. Lorsque les dieux faisaient l'homme. Paris: Éditions Gallimard, 1993.

CAD. Chicago Assyrian Dictionary. Chicago: Oriental Institute, 21 vol., 1956-1995.

FLANDRIN, J.-L.; MONTANARI, M. História da Alimentação. Tradução de Luciano V. Machado e Guilherme J. F. Teixeira. São Paulo: Estação Liberdade, 1998.

GLASSNER, J.-J. La Mésopotamie. Paris: Les Belles Lettres, 2002.

La réception de l'hôte, le vivre et le couvert. Dossiers d'Archéologie, n. 280, 2003. p. 44-47.

HALLO, W. Origins - The Ancient Near Eastern background of some Modern Western institutions. Leiden-New York-Köln: E. J. Brill, 1996.

JOANNÈS, F. A função social do banquete nas primeiras civilizações. In: FLANDRIN, J.-L.; MONTANARI, M. História da Alimentação. Tradução de Luciano V. Machado e Guilherme J. F. Teixeira. São Paulo: Estação Liberdade, 1998, p.54-67.

Laffont, 2001.

Dictionnaire de la Civilisation Mésopotamienne. Paris: Robet

LABAT, R.; MALBRAN-LABAT, F. Manuel d'Épigraphie Akkadienne. Paris: Librairie Orientaliste Paul Geuthner, 1988.

LAYARD, A.H. The Monuments of Niniveh. London: John Murray, 1853.

LION, B.; MICHEL, C. Un banquet à la cour assyrienne. Dossiers d'Archéologie. Dijon: Éditions Faton, n. 280, p. 24-31, 2003.

MALBRAN-LABAT, F. Gilgamesh. Paris: Éditions du Cerf, s.d.

OPPENHEIM, A. Leo. Ancient Mesopotamia - Portrait of a Dead Civilization. Chicago \& London: The University of Chicago Press, 1977.

PEINADO, F. L. Enuma Elish. Madrid: Editorial Trotta, 1994.

POZZER, K.M.P. O Banquete do Rei e a Política nos Tempos de Paz. In: Cerqueira, F.V.; Gonçalves, A.T.; Nobre, C.K.; Silva, G.J.; Vargas, A.Z. 
Guerra e Paz no Mundo Antigo. Pelotas: Leeparq/UFPel, IMP, 2007. p. 139152.

A Epopeia de Gilgameš Amizade e Morte na Mesopotâmia In: SANTOS, D (org.). Grandes Epopeias da Antiguidade e do Medievo. Blumenau: Edifurb, 2014, p. 42-53.

PRITCHARD, J. B. Ancient Near Eastern Texts Relating to the Old Testament. Princeton: Princeton University Press, 1950.

ROAF, M. Atlas de la Mésopotamie. Paris: Brepols, 1991.

SIGRIST, M. Les sattukku dans l'Ešumeša durant la période d'Isin et Larsa. BiMes 11, Malibu, 1984.

STOL, M. Private life in Ancient Mesopotamia. In: SASSON, J. M. (Editor). Civilizations of the Ancient Near East. New York: Scribner, 2000. p.485-501.

ZIEGLER, N. Diplomatie à la table du roi. Dossiers d'Archéologie. Dijon: Édition Faton, n. 280, p. 16-23, 2003. 